\title{
Síndromes de polinização ocorrentes em uma área de Mata Atlântica, Paraíba, Brasil
}

\author{
Jussiara de Lima Oliveira Araújo ${ }^{1 *}$ \\ Zelma Glebya Maciel Quirino ${ }^{2}$ \\ Pedro da Costa Gadelha Neto ${ }^{3}$ \\ Afrânio César de Araújo ${ }^{4}$ \\ Universidade Estadual a Paraíba \\ Rua Maria das Mercês Rodrigues, 260, CEP 58417-685, Campina Grande - PB, Brasil \\ ${ }^{2}$ Universidade Federal da Paraíba, Campus IV Litoral Norte, Rio Tinto - PB, Brasil \\ ${ }^{3}$ Jardim Botânico Benjamim Maranhão, João Pessoa - PB, Brasil \\ ${ }^{4}$ Universidade Federal do Rio Grande do Norte, Campus Macaíba \\ Escola Agrícola de Jundiaí, Macaíba - RN, Brasil \\ *Autor para correspondência \\ jussiaralima@hotmail.com
}

Submetido em 02/03/2009

Aceito para publicação em 16/06/2009

\section{Resumo}

Objetivou-se identificar as síndromes de polinização das espécies vegetais ocorrentes na Mata do Buraquinho, PB. Analisaram-se as relações existentes entre os atributos florais das espécies vegetais e as recompensas oferecidas ao polinizador. Das 88 espécies estudadas 50,2\% eram de flores claras e 48,7\% vistosas, representadas principalmente por árvores e arbustos. A maioria das espécies (66\%) apresentou flores pequenas, seguidas de flores grandes e médias. A maior parte dos arbustos, trepadeiras e ervas apresentam flores pequenas. A unidade de polinização mais frequente foi a coletivista (71,5\%). As árvores obtiveram porcentagem maior entre as espécies coletivistas (30,1\%). O tubo foi o tipo floral predominante $(72,7 \%)$, seguido de disco $(14,7 \%)$, estandarte $(11,3 \%)$ e inconspícuo (1,3\%). Flores actinomorfas foram a maioria $(60,2 \%)$ enquanto que $38,6 \%$ foram zigomorfas. Quanto aos sistemas sexuais $88,6 \%$ foram de flores hermafroditas enquanto que $8 \%$ foram monóicas e apenas 3,4\% dióicas. O recurso mais frequente foi néctar $(64,7 \%)$, seguido de pólen (14,7\%), néctar/ pólen $(12,5 \%)$ e óleo $(1,1 \%)$. Entre as síndromes de polinização a entomofilia predominou, sendo melitofilia $57 \%$, psicofilia $14,7 \%$ e outros insetos $16,8 \%$. A melitofilia foi mais representativa entre as árvores. A ornitofilia e a quiropterofilia, que representaram, respectivamente, 7 e 3,4\%, não foram encontradas entre os arbustos.

Unitermos: floresta tropical, biologia floral, sistemas de polinização

\section{Abstract}

Pollination syndromes in a Rainforest Area, Paraíba, Brazil. This work aimed to identify the pollination syndromes of species in Mata do Buraquinho, PB, Brazil. The relationships among the floral attributes of the vegetable species and the rewards offered to the pollinators were evaluated. Within the 88 species studied, $50.2 \%$ were whitish flowers and $48.7 \%$ were conspicuous, mainly represented by trees and shrubs. The majority of the species $(66 \%)$ had small flowers, followed by large and medium flowers. Most of the shrubs, vines and herbs 
had small flowers. The collectivist pollination unit was the most representative $(71.5 \%)$. The trees obtained the highest percentage among the collectivist species $(30.1 \%)$. The tube was the predominant kind of flower $(72.7 \%)$, followed by the disk, the flag and the inconspicuous. The majority of the flowers were actinomorphic $(60.2 \%)$, while $38.6 \%$ were zigomorphic. Regarding the sexual systems, $88.6 \%$ were hermaphroditic flowers, while $8 \%$ were monoecious and only $3.4 \%$ were dioecious. The most frequent resource was nectar $(64.7 \%)$, followed by pollen (14.7\%), nectar/pollen (12.5\%) and oil (1.1\%). Entomophilia was the predominant pollination syndrome, followed by melitophilia (57\%), other insects (16.8\%) and psicophilia (14.7\%). Melitophilia was the most representative among the trees. Ornithofilia represented $7 \%$ and chiropterophilia $3.4 \%$. Neither ornithofilia nor chiropterophilia were found among the shrubs.

Keys words: floral biology, pollination systems, tropical forest

\section{Introdução}

A polinização pode ser definida como a transferência de grãos de pólen das anteras para o estigma, o que pode se dar em uma mesma flor ou entre flores distintas (Endress, 1994). Atributos florais como: odor, cor, disponibilidade de néctar, formato da flor e outros recursos estão relacionados aos polinizadores (Faegri e Pij1, 1979).

Os recursos florais mais procurados pelos animais polinizadores são pólen e néctar. Além destes, outros recursos primários da flor também podem ser citados, como: óleos, resinas, perfumes, gomas, locais para acasalamento e deposição de larvas (Machado e Lopes, 1998). Estes recursos satisfazem, de maneira geral, as necessidades fisiológicas dos polinizadores e os atrativos secundários (odor e cor) advertem os polinizadores para presença dos atrativos primários (Faegri e Pij1, 1979).

As síndromes de polinização podem ser de vários tipos: melitofilia (abelhas), cantarofilia (besouros), miofilia e saprofilia (moscas), psicofilia (borboletas), esfingiofilia (esfingídeos), ornitofilia (pássaros, em especial, beija-flores), quiropterofilia (morcegos) e falenofilia (mariposas), (Faegri e Pijl ,1979).

Cada espécie ou família de planta apresenta características morfológicas e fisiológicas específicas que podem atrair certos grupos de visitantes e podem revelar importantes implicações não apenas na relação planta-animal, mas também no sucesso reprodutivo da planta (Barbosa, 1997). A diversidade dos tipos florais está associada com o desenvolvimento sensorial dos polinizadores, particularmente, aqueles relacionados com a capacidade de distinção e memorização de certos padrões florais (Ramírez et al., 1990).
A Mata Atlântica apresenta maior diversidade biológica relativa das florestas tropicais conhecidas, no entanto, sua extensão foi reduzida a 7,6\% de sua extensão original devido a forte pressão antrópica (Machado e Lopes, 2003).

A Mata do Buraquinho, por se tratar de um fragmento florestal em uma área urbana, sofre a ação direta dos efeitos antrópicos, tais como a deposição e queima de diversos tipos de lixo; a retirada de madeira para serviços domésticos das comunidades que vivem às margens da mata e a produção de valas no solo, que intensifica os processos de erosão e o escoamento de dejetos direcionados à mata.

Estudos de biologia floral no estado da Paraíba ainda são insipientes, principalmente no que se refere à Mata Atlântica, sendo assim, mais pesquisas são necessárias já que a ecologia da polinização é, sobretudo, de grande importância para compreensão da estrutura de comunidades vegetais naturais (Martins, 2005).

Este estudo teve como objetivo identificar as síndromes de polinização das espécies vegetais ocorrentes na Mata do Buraquinho, Paraíba, Brasil.

\section{Material e Métodos}

O trabalho de campo foi realizado no Jardim Botânico Benjamin Maranhão (Mata do Buraquinho), localizado no município de João Pessoa - PB (0706'S e $\left.34^{\circ} 52^{\prime} \mathrm{W}\right)$. A área do Jardim Botânico abrange cerca de 417 ha e uma altitude de $45 \mathrm{~m}$, na formação geológica do baixo planalto costeiro (Barbosa, 1996).

A Mata do Buraquinho é um remanescente das florestas pluviais costeiras do Nordeste brasileiro. O 
período mais chuvoso concentra-se entre os meses de Março e Agosto, com o acumulado de $153 \mathrm{~mm}$ e um período de pouca pluviosidade nos meses de Setembro a Abril, registrando os menores índices $(100 \mathrm{~mm})$. As temperaturas médias da Paraíba neste período variaram entre a mínima de $19,3^{\circ} \mathrm{C}$ e a máxima de $32,7^{\circ} \mathrm{C}$ (Barbosa, 1996). O solo da área estudada é classificado como Podzólico Vermelho Amarelo. A textura varia de franco arenoso nas camadas mais superficiais a argiloarenoso nas mais profundas.

As atividades de campo foram realizadas entre Agosto/2006 e Maio/2007 com intervalos bimestrais. Foram coletadas cerca de dez flores e/ou botão, de cada espécie em fenofase de floração de forma aleatória nas trilhas existentes na Mata do Buraquinho. Durante o trabalho em campo, flores e botões foram fixados em álcool (70\%) para análises complementares no laboratório de Botânica da Universidade Estadual da Paraíba.

Foram estudadas 88 espécies, incluindo 29 árvores, 15 arbustos, 23 ervas e 21 trepadeiras, distribuídas em 43 famílias e 80 gêneros. Para cada espécie foram registrados atributos florais como forma, tamanho, sistemas sexuais, cor e recompensa floral. E também outros caracteres morfológicos, como: simetria e presença de odor.

As classificações de tamanho seguiram o proposto por Machado e Lopes $(2003 ;$ 2004), sendo as flores distribuídas nas seguintes classes: pequenas $(\leq 10 \mathrm{~mm})$, médias $(>10 \mathrm{~mm} \leq 20 \mathrm{~mm})$ e grandes $(>20 \mathrm{~mm})$.

As flores estudadas seguiram as seguintes categorias de cores: claras, incluindo as cores branca e esverdeada e vistosas, abrangendo as cores amarela, laranja, lilás (incluindo azul), vermelha e rosa (compreendendo claro e choque), considerando-se a mais evidente de acordo com Machado e Lopes $(2003 ;$ 2004).

As flores das espécies estudadas foram classificadas de acordo com os seguintes tipos florais: tubo, pincel, disco, estandarte ou inconspícua, este último, compreendendo flores muito pequenas. Quanto à oferta de recursos foram descritos quatro tipos de flores: com pólen, néctar, óleo ou néctar/pólen. (Faegri e Pij1 1979). Apenas o recurso principal foi considerado.

Analisou-se também o sistema reprodutivo das espécies, classificando-o como hermafrodita, dióico ou monóico. De acordo com Machado e Lopes (2003; 2004), Classificam-se também os possíveis sistemas de polinização (melitofilia, cantarofilia, miofilia, psicofilia, falenofilia, ornitofilia, quiropterofilia) para cada espécie estudada.

As espécies vegetais coletadas foram identificadas pelo taxonomista do Jardim Botânico, Pedro Gadelha Neto, de acordo com o sistema de classificação Angiosperm Phylogeny Group II (2003). O material testemunho encontra-se depositado na coleção da Mata do Buraquinho (Jardim Botânico Benjamin Maranhão), do Herbário Lauro Pires Xavier (JPB) da UFPB (Universidade Federal da Paraíba), João Pessoa - PB.

\section{Resultados e Discussão}

Foram analisadas 88 espécies, pertencentes a 43 famílias e 78 gêneros, incluindo árvores (29\%), trepadeiras (23\%), arbustos (24\%) e ervas (24\%) (Tabela 1). As espécies estudadas representaram $15,7 \%$ do total de espécies existentes na Mata do Buraquinho, de acordo com a lista das espécies do Jardim Botânico, versão outubro de 2006. 
TABELA 1: Nome popular e hábito das espécies estudadas na Mata do Buraquinho, João Pessoa, PB.

\begin{tabular}{|c|c|c|}
\hline Famílias e Espécies & Hábito & Material de Referência \\
\hline \multicolumn{3}{|l|}{ Acanthaceae } \\
\hline Ruellia geminiflora H. B. \& K & erva & Gadelha Neto 789 \\
\hline Thunbergia fragrans $\mathrm{R}$. & trep & $*$ \\
\hline \multicolumn{3}{|l|}{ Anacardiaceae } \\
\hline Schinus terebinthifolius Raddi & árvore & Gadelha Neto 1120 \\
\hline \multicolumn{3}{|l|}{ Annonaceae } \\
\hline Guatteria schomburgkiana Mart. & árvore & Barbosa 1465 \\
\hline Xylopia laevigata (Mart.) R.E.Fr. & árvore & Gadelha Neto \& Leite da Luz 1037 \\
\hline \multicolumn{3}{|l|}{ Apocynaceae } \\
\hline Mandevilla scabra K. & trep & Gadelha Neto 1011 \\
\hline Himatanthus phagedaenicus $\mathrm{W}$. & árvore & Gadelha Neto et al 1010 \\
\hline \multicolumn{3}{|l|}{ Araceae } \\
\hline Syngonium podophyllum Schott & trep & Gadelha Neto \& Costa-Santos 737 \\
\hline \multicolumn{3}{|l|}{ Aristolochiaceae } \\
\hline Aristolochia pappilaris Mast. & trep & Gadelha Neto et al 1296 \\
\hline \multicolumn{3}{|l|}{ Asteraceae } \\
\hline Centratherum punctatum Cass. & erva & Costa-Santos 116 \\
\hline Emilia sonchifolia (L.) DC. & erva & Pereira 28 \\
\hline Sphagneticola trilobata (L.) & erva & * \\
\hline \multicolumn{3}{|l|}{ Bignoniaceae } \\
\hline Arrabidaea sp. & trep & * \\
\hline Crescentia cujete L. & árvore & Gadelha Neto et al. 1579 \\
\hline Phryganocydia corymbosa (Vent.) B. & trep & Gadelha Neto 1527 \\
\hline Tabebuia roseo alba (Ridl.) S. & árvore & Gadelha Neto 1305 \\
\hline \multicolumn{3}{|l|}{ Boraginaceae } \\
\hline Cordia superba Cham. & arbusto & Gadelha Neto et al. 992 \\
\hline Cordia cf. polycephala (Lam.) I.M. & arbusto & * \\
\hline Cordia multispicata Cham. & erva & Gadelha Neto \& Costa-Santos 741 \\
\hline \multicolumn{3}{|l|}{ Cecropiacea } \\
\hline Cecropia cf. palmata Willd & árvore & $*$ \\
\hline \multicolumn{3}{|l|}{ Celastraceae } \\
\hline Fraunhofera sp1. & árvore & Gadelha Neto et al 1229 \\
\hline Fraunhofera sp2. & árvore & Gadelha Neto et al 1230 \\
\hline \multicolumn{3}{|l|}{ Chrysobalanaceae } \\
\hline Hirtella racemosa Lam. & árvore & Gadelha Neto 694 \\
\hline \multicolumn{3}{|l|}{ Convolvulaceae } \\
\hline Ipomoea alba & trep & Gadelha Neto 1246 \\
\hline \multicolumn{3}{|l|}{ Cucurbitaceae } \\
\hline Momordica charantia $\mathrm{L}$. & trep & Gadelha Neto 812 \\
\hline \multicolumn{3}{|l|}{ Cuscutaceae } \\
\hline Cuscuta sp. & trep & Gadelha Neto et al. 1063 \\
\hline \multicolumn{3}{|l|}{ Dilleniaceae } \\
\hline Tetracera sellowiana Schltdl. & trep & Gadelha Neto 1347 \\
\hline
\end{tabular}




\begin{tabular}{|c|c|c|}
\hline \multicolumn{3}{|l|}{ Euphorbiaceae } \\
\hline Chamaesyce hyssopifolia (L.) Small & erva & Gadelha Neto 1481 \\
\hline Cnidoscolus urens (L.) Arthur & erva & Gadelha Neto 811 \\
\hline Croton sellowii Baill. & arbusto & Veloso \& Pontes (JPB 33287) \\
\hline Dalechampia scandens L. & trep & Gadelha Neto \& Costa-Santos 831 \\
\hline Euphorbia heterophylla L. & erva & Gadelha Neto \& Costa-Santos 739 \\
\hline Pogonophora schomburgkiana M. & árvore & Gadelha Neto \& Lima 687 \\
\hline \multicolumn{3}{|l|}{ Fabaceae } \\
\hline Calopogonium mисипоides Desv. & trep & Gadelha Neto et al. 1563 \\
\hline Clitoria fairchildiana $\mathrm{H}$. & árvore & Gadelha Neto \& Costa-Santos 827 \\
\hline Dioclea violacea Mart. ex. Benth. & trep & Gadelha Neto \& Leite da Luz 1050 \\
\hline Dioclea virgata (Rich.) A. & trep & Gadelha Neto et al 1126 \\
\hline Mucuna sloanei Fawc. \& Rendle & trep & Gadelha Neto et al. 916 \\
\hline Rhynchosia phaseoloides (Sw.) DC. & trep & Gadelha Neto et al. 709 \\
\hline Chamaecrista desvauxii (Collad.) $\mathrm{K}$. & arbusto & Gadelha Neto 761 \\
\hline Chamaecrista flexиоsa (L.) Greene & erva & Gadelha Neto et al. 1022 \\
\hline Senna georgica Irwin \& Barneby & árvore & Gadelha Neto \& Lima 658 \\
\hline Senna quinquangulata (Rich.) H. & trep & Gadelha Neto 816 \\
\hline Leucaena leucocephala (Lam.) de Wit & árvore & Gadelha Neto et al. 1129 \\
\hline Mimosa caesalpiniifolia Benth & árvore & Gadelha Neto \& Costa-Santos 826 \\
\hline \multicolumn{3}{|l|}{ Heliconiaceae } \\
\hline Heliconia psittacorum L.f. & erva & Gadelha Neto \& Montenegro 649 \\
\hline \multicolumn{3}{|l|}{ Lauraceae } \\
\hline Ocotea gardneri (Meisn.) Mez & arbusto & Gadelha Neto et al. 716 \\
\hline \multicolumn{3}{|l|}{ Lecythidaceae } \\
\hline Eschweilera ovata (Cambess.) Miers & árvore & Gadelha Neto et al. 696 \\
\hline \multicolumn{3}{|l|}{ Loganiaceae } \\
\hline Spigelia anthelmia $\mathrm{L}$. & erva & Gadelha Neto et al. 1006 \\
\hline \multicolumn{3}{|l|}{ Lythraceae } \\
\hline Cuphea flava Spreng & erva & Gadelha Neto et al 1012 \\
\hline \multicolumn{3}{|l|}{ Malpighiaceae } \\
\hline Byrsonima gardneriana Juss. & arbusto & Gadelha Neto 763 \\
\hline Stigmaphyllon paralias A.Juss. & arbusto & Gadelha Neto et al. 969 \\
\hline \multicolumn{3}{|l|}{ Malvaceae } \\
\hline Pavonia fruticosa (Mill.) & erva & Gadelha Neto \& Costa-Santos 891 \\
\hline Malvastrum cf. scabrum (Cav.) A. & erva & Gadelha Neto \& Lima 1344 \\
\hline Eriotheca crenulaticalyx A. & árvore & $*$ \\
\hline Guazuma ulmifolia Lam. & árvore & * \\
\hline Luehea ochrophylla Mart. & árvore & $*$ \\
\hline \multicolumn{3}{|l|}{ Melastomataceae } \\
\hline Miconia ciliata (L.C.Rich.) DC. & arbusto & Gadelha Neto 656 \\
\hline Comolia sp. & erva & Gadelha Neto 762 \\
\hline \multicolumn{3}{|l|}{ Meliaceae } \\
\hline Guarea guidonia (L.) Sleumer & árvore & Gadelha Neto et al. 1075 \\
\hline \multicolumn{3}{|l|}{ Menispermaceae } \\
\hline Cissampelos glaberrima A.St.-Hil. & trep & Gadelha Neto et al. 1294 \\
\hline \multicolumn{3}{|l|}{ Myrtaceae } \\
\hline Campomanesia dichotoma (Berg) M. & árvore & Barbosa 1266 \\
\hline Myrcia sylvatica (G.Mey.) DC. & árvore & Carneiro (JPB 1785) \\
\hline Psidium guajava $\mathrm{L}$. & árvore & Gadelha Neto 1200 \\
\hline
\end{tabular}




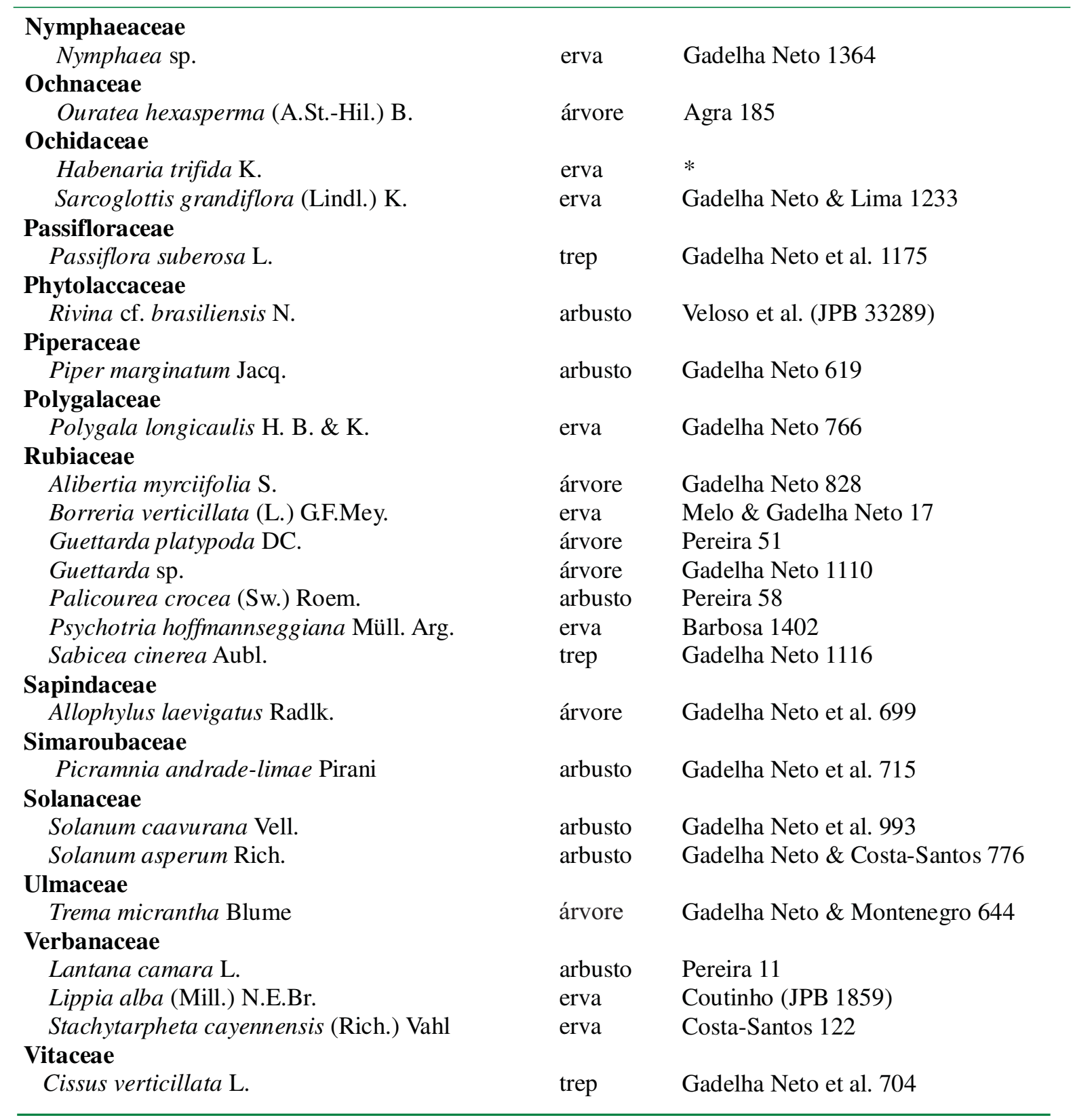




\section{Atributos florais}

\section{Cor}

A porcentagem de flores claras (incluindo espécies de flores brancas ou esverdeadas) foi de $51,3 \%$ enquanto as flores vistosas (amarelas, vermelhas, rosas, lilases) somaram $48,7 \%$. Foi encontrada uma alta proporção de espécies com flores brancas $(40 \%)$, seguidas de amarelas $(27,2 \%)$, lilases $(17 \%)$, esverdeadas $(10,2 \%)$, rosas $(3,4 \%)$ e vermelhas $(1,1 \%)$. As flores aclamídeas estiveram na frequência de $1,1 \%$.

A predominância de flores claras encontradas neste estudo assemelha-se a resultados observados por Cara (2006) em mata úmida alagoana e por SilberbauerGottsberger e Gottsberger (1988) no Cerrado. Diferente do encontrado neste estudo, flores vistosas têm sido observadas em floresta seca por Machado e Lopes (2003; 2004), e também em mata úmida tropical (Ramírez et al., 1990). Por isso Momose et al. (1998) afirma que as semelhanças de cores encontradas em ambientes diversos confirmam a pouca significância entre este atributo e os sistemas de polinização.

As árvores e os arbustos, em sua maioria, apresentaram flores claras (branca ou esverdeada), contudo, as ervas obtiveram um percentual alto de flores vistosas, enquanto que para as trepadeiras os valores de flores claras e vistosas foram iguais (Tabela 2).

De acordo com Faegri e Pijl (1979) e Proctor et al. (1996) a visão colorida e discriminativa foi comprovada em vários grupos de insetos, a maioria sensível ao ultravioleta, ao azul, ao verde e ao amarelo, mas com pouca ou nenhuma sensibilidade ao vermelho, que atrai preferencialmente os pássaros, os quais não percebem o ultravioleta.

\section{Tamanho floral}

A maioria das espécies (66\%) apresentou tamanho pequeno, seguida das flores grandes $(19,3 \%)$ e médias $(14,7 \%)$. Diferenciando entre os hábitos, a maior parte dos arbustos, trepadeiras e ervas apresentam flores pequenas, enquanto que para as árvores o percentual de flores médias foi um pouco maior. Entre os arbustos a porcentagem de flores grandes foi pequena, já entre as ervas, os valores de flores grandes e médias foram iguais (Tabela 2).

TABELA 2: Relação percentual (\%) entre o tamanho, a unidade de polinização, os tipos florais, os recursos oferecidos, as cores florais, os sistemas sexuais com os hábitos das espécies estudadas na Mata do Buraquinho, João Pessoa, PB.

\begin{tabular}{lccccc}
\hline & Árvore & Arbusto & Trepadeira & Erva \\
\hline Pequena & 65,3 & 71,4 & 55,0 & 71,4 \\
Média & 76,0 & 19,0 & 20,0 & 14,0 \\
Grande & 27,0 & 09,5 & 25,0 & 14,3 \\
\hline Individual & 28,0 & 20,0 & 20,0 & 32,0 \\
Coletivista & 30,1 & 25,3 & 23,8 & 20,6 \\
\hline Tubo & 73,0 & 81,0 & 60,0 & 76,1 \\
Disco & 19,2 & 09,5 & 20,0 & 09,5 \\
Estandarte & 07,7 & 04,8 & 20,0 & 14,3 \\
Inconspícua & 00,0 & 04,8 & 00,0 & 00,0 \\
\hline Néctar & 77,0 & 62,0 & 65,0 & 71,4 \\
Pólen & 07,7 & 28,5 & 10,0 & 23,8 \\
Néctar/pólen & 15,3 & 04,8 & 25,0 & 4,80 \\
Óleo & 00,0 & 04,8 & 00,0 & 00,0 \\
\hline Clara & 61,5 & 52,0 & 50,0 & 38,0 \\
Vistosa & 39,0 & 47,6 & 50,0 & 62,0 \\
\hline Hermafrodita & 88,4 & 90,4 & 90,0 & 85,7 \\
Dióica & 07,7 & 04,8 & 00,0 & 00,0 \\
Monóica & 03,8 & 04,8 & 10,0 & 14,2 \\
\hline
\end{tabular}

Ipomoea alba L. (Convolvulaceae)e Campomanesia dichotoma (Berg) Mattos (Myrtaceae) foram as espécies trepadeira e arbórea, respectivamente, com flores maiores, enquanto que Xylopia laevigata (Mart.) R.E. Fr. (Annonaceae) e Picramnia andrade-limae Pirani (Simaroubaceae) são exemplos de espécies que apresentaram as menores flores.

Os percentuais encontrados neste estudo assemelham-se aos estudos de Cara (2006) realizados em mata úmida, mas diferem dos resultados observados por Machado e Lopes $(2003 ; 2004)$, onde mais de $54 \%$ foram de flores grandes e muito grandes. Segundo Opler (1980), há de fato uma relação entre tamanhos florais e seus visitantes ou polinizadores, como por exemplo, o comprimento da probóscide de borboletas ou do bico dos beija-flores. Flores pequenas são geralmente polinizadas por pequenos insetos, mas se organizadas em inflorescências podem permitir a visita de insetos 
maiores. Como observado nas espécies Hirtella racemosa Lam. (Chrysobalanaceae) e Senna geogica Irwin e Barneby (Caesalpinaceae) encontradas neste estudo.

\section{Unidade de polinização}

O tipo coletivista (formando inflorescências) foi mais representativo, encontrado em $71,5 \%$ das espécies, em contraste com os $28,4 \%$ das espécies com flores individuais.

As árvores obtiveram uma porcentagem de espécies coletivistas maior que as dos demais hábitos (30,1\%), as flores individuais tiveram porcentagens baixas em relação às trepadeiras e arbustos $(20 \%$ cada $)$, enquanto as ervas atingiram $32 \%$ das espécies com flores individuais (Tabela 2).

Ao contrário deste estudo, Machado e Lopes (2003; 2004), em área de Caatinga, encontraram uma quantidade mais representativa de flores individuais, mais de $80 \%$ das espécies. Contudo, de modo semelhante a este estudo, Alvino (2005), realizando trabalhos em mata de transição, observou que quase $80 \%$ das espécies formavam inflorescências.

Flores agrupadas em inflorescências aumentam a visibilidade floral, aumentando assim, o potencial de atração dos polinizadores, mas essa característica pode contribuir para que a flor receba pólen da mesma planta, diminuindo a variabilidade genética da comunidade.

\section{Tipos florais}

Foi observada uma predominância de flores do tipo tubo $(72,7 \%)$, seguidas de disco $(14,7 \%)$, estandarte $(11,3 \%)$ e inconspícuas $(1,3 \%)$ A relação entre os hábitos e os tipos florais estudados mostra que em todos eles a flor do tipo tubo predomina. Apenas uma espécie arbustiva apresentou flor inconspícua e, entre as trepadeiras, os tipos disco e estandarte obtiveram porcentagens iguais (20\%) (Tabela 2).

Resultados opostos aos observados ao longo deste estudo foram encontrados por Cara (2006), onde o tipo floral predominante foi o inconspícuo. Machado e Lopes (2003; 2004), encontraram maior número de flores abertas $(25,7 \%)$, seguidas de tubulosas e estandarte. Determinados tipos florais restringem o acesso ao recurso e com isso acabam selecionando os visitantes, reduzindo, portanto, a atuação de possíveis pilhadores (p.ex., beija-flores), evitando assim, o roubo de néctar.

\section{Simetria}

Flores actinomorfas foram encontradas na maioria das espécies $(61,4 \%)$, enquanto 38,6 \% apresentavam flores zigomorfas (Tabela 2).

No presente estudo a porcentagem de espécies com flores actinomorfas foi semelhante a outros estudos realizados em comunidades arbustivas (Machado e Lopes, 2003; Alvino, 2005). A simetria do tipo actinomorfa esteve associada a alguns tipos florais como tubo e disco, visto que a simetria zigomorfa esteve associada aos tipos estandarte e inconspícuo.

\section{Sistemas sexuais}

Foi observada uma maior frequência de flores hermafroditas $(88,6 \%)$, enquanto que $(8 \%)$ foram monóicas e apenas $(3,4 \%)$ dióicas, representadas por Schinus terebinthifolius Raddi. (Anacardiaceae), Guettarda sp. (Rubiaceae) e Picramnia andradelimae Pirani. (Simaroubaceae), onde as duas primeiras são árvores e apenas a última é arbustiva. Espécies hermafroditas obtiveram grandes porcentagens em todos os hábitos da comunidade (Tabela 2). Por outro lado, foi encontrada uma pequena quantidade de espécies monóicas (sete espécies).

Observou-se uma espécie arbórea (Pogonophora schomburgkiana Miers ex Benth), um arbusto (Croton sellowii Baill.), duas trepadeiras (Momordica charantia L. e Cissampelos glaberrima A. St.-Hil.) e três ervas (Cnidoscolus urens (L.) Arthur, Chamaesyce hyssopifolia L e Euphorbia heterophylla L.) (Tabela 1).

Em outras áreas de mata úmida foram encontrados resultados para espécies hermafroditas semelhantes aos deste estudo, mas os resultados foram mais próximos do encontrado por Quirino (2006), apesar desse ambiente ser de mata seca. As espécies dióicas foram pouco representadas neste estudo. 
De modo geral, a distribuição dos sistemas sexuais mostra certa semelhança tanto em matas secas como em matas úmidas. A dioicia pode ser associada à polinização mais generalista (Bawa e Opler, 1975). Segundo Bertin (1989), cerca de 70\% das plantas são hermafroditas. As vantagens para esse sistema incluem a necessidade de apenas um perianto e, em alguns casos, uma única dose de néctar para ambos os sexos florais, ao contrário das flores com funções sexuais separadas. Além disso, em uma única visita o polinizador pode tanto depositar o pólen no estigma quanto retirar pólen das anteras.

\section{Recursos florais}

Foi registrada uma grande variedade de tipos de recompensas florais, como néctar, pólen, néctar/pólen e óleo. O recurso mais frequente foi o néctar $64,7 \%$, seguido de pólen $(14,7 \%)$, néctar/pólen (12,5\%) e óleo $(1,1 \%)$.

Nas árvores e nos demais hábitos houve uma porcentagem alta de flores ofertando néctar. Entre os arbustos e as ervas a porcentagem de flores com néctar/ pólen foi baixa e apenas uma espécie em meio aos arbustos ofertou óleo (Tabela 2).

Ao contrário disto, Cara (2006), em mata úmida observou taxas de néctar/pólen bem maiores que as verificadas neste estudo. Resultados semelhantes para néctar, pólen e néctar/pólen foram encontrados em outros trabalhos em diferentes ecossistemas, como Cerrado, em Silberbauer-Gottsberger e Gottsberger (1988) e Caatinga, em Machado e Lopes (2003). De acordo com Machado e Lopes (2003), o pólen, como recompensa floral, geralmente é oferecido por espécies de anteras poricidas, polinizadas por abelhas que vibram o corpo durante as visitas. Neste estudo podem ser citadas as espécies Chamaecrista desvauxii (Collad.) Killip (Caesalpiniaceae), Miconia ciliata (L.C.Rich.) D.C. e Comolia sp (Melastomaceae) com este tipo de condição.

O recurso que predominou durante todo o período de estudo foi o néctar, tendo sua maior porcentagem no mês de abril. O pólen também foi oferecido durante todo o ano de estudo, encontrando-se mais presente nos meses de fevereiro e Maio. O néctar/pólen foi maior representado no mês de Agosto, porém no mês de Maio não foi analisada nenhuma espécie com este recurso. O óleo foi oferecido no período chuvoso por apenas uma espécie Byrsonima gardneriana Juss. (Malpighiaceae) (Figura 1).

No período chuvoso (Agosto/Maio) as porcentagens de plantas que ofertavam néctar permaneceram altas. No período seco (Novembro/Fevereiro/Abril) os valores relativos a néctar/pólen e pólen mantiveram-se mais ou menos constantes, sofrendo uma pequena queda no mês de Abril. Já em Maio (período considerado chuvoso) não houve a presença de flores ofertando néctar/pólen (Figura 1).

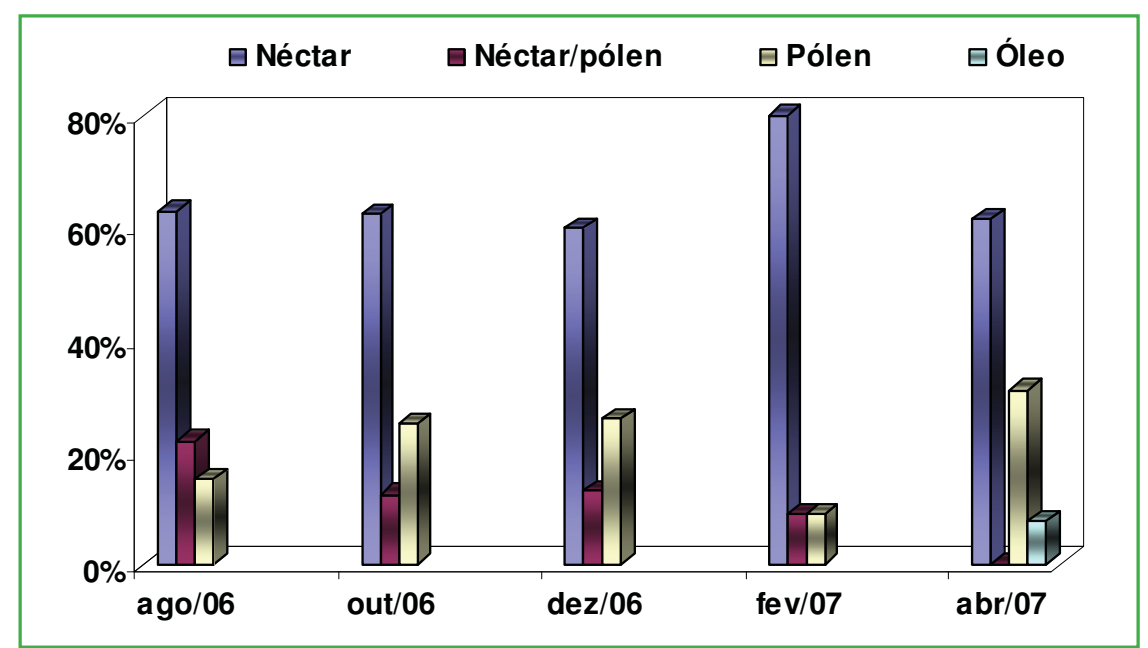

FIGURA 1: Relação entre o período de estudo e as recompensas florais das espécies estudadas na Mata do Buraquinho, João Pessoa, PB. 
O pólen (rico em proteínas) e o néctar (rico em açúcares) são extremamente importantes para os polinizadores, visto que estes recursos são utilizados como fontes nutritivas mais comuns. As plantas ainda ofertam óleo, que é rico em lipídios, sendo, portanto, muito energético, podendo ser encontrado em oito famílias de Angiospermas, mais especificamente nas Malpighiaceae. Essa recompensa é geralmente coletada por abelhas para alimentação de larvas.

\section{Síndromes de polinização}

A polinização por insetos (entomofilia) foi o sistema de polinização mais frequente, podendo ocorrer em $88,5 \%$ das espécies estudadas, seguida de polinização por beija flores (ornitofilia) (7\%), morcegos (quiropterofilia) $(3,0 \%)$ e $1,1 \%$ para a única espécie anemófila (polinização pelo vento) estudada. Entre as espécies entomófilas, a polinização por abelhas foi mais representativa, com 57\%, seguida de borboletas (Psicofilia) com 14,7\%, moscas (miofilia), mariposas (falenofilia) e besouros (cantarofilia) apresentaram 5,6\% cada (Figura 2).

A síndrome de polinização por abelhas foi a mais representativa na Mata do Buraquinho, semelhante ao encontrado em diversas outras comunidades tropicais como em floresta úmida por Bawa et al. (1985), na caatinga por Quirino (2006), no cerrado por Silberbauer-Gottsberger e Gottsberger (1988) e na floresta seca da Costa Rica, por Kang e Bawa (2003). Confirmando-se, então, que a polinização por insetos, em especial por abelhas, é o sistema de polinização mais representativo, independente do ambiente estudado (Cara, 2006).

Neste estudo as flores polinizadas por abelhas foram, de modo geral, brancas, amarelas, verde, lilases e róseas; simetria actinomorfa ou zigomorfa; ofertando néctar, pólen, néctar/pólen e óleo; tubulares, disco ou estandarte; todos os tamanhos; unidade de polinização individual ou coletivista e sistema sexual hermafrodita, monóica ou dióica. Dentre as espécies melitófilas, ofertando néctar, na Mata do Buraquinho estão: Borreria verticillata (L.) G.F. Mey., Calopogonium mucunoides Desv., Cissus verticillata L., Dioclea violacea Mart. ex. Benth. O maior número de espécies melitófilas foi encontrado entre as árvores, porém, valores iguais para essa síndrome foram encontrados em arbustos, trepadeiras e ervas (Figura 3).

Para quiropterofilia foi encontrada uma porcentagem pequena em relação aos estudos realizados por Cara (2006), cerca de 7,5\%; porém, resultados semelhantes foram encontrados por Bawa et al. (1985), (3,0\%), e Silberbauer-Gottsberger e Gottsberger (1988), (1,7\%).

$\mathrm{Na}$ Mata do Buraquinho os morcegos podem ser polinizadores das seguintes espécies Crescentia cujete L. (Bignoniaceae), Eriotheca crenulaticalyx A. Robyns. (Malvaceae) e Luehea ochrophylla Mart. (Tiliaceae).

A ornitofilia apresentou um valor aproximado ao encontrado por Quirino (2006) na caatinga, mas apresentou uma porcentagem alta quando comparado com os estudos de Bawa et al. (1985), SilberbauerGottsberger e Gottsberger (1988) e Kang e Bawa (2003).

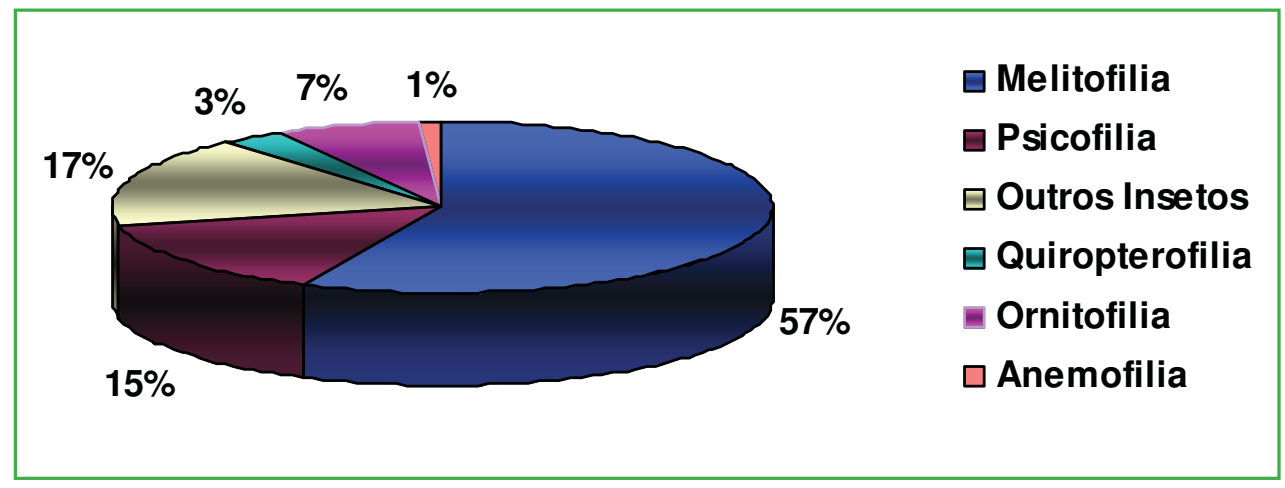

FIGURA 2: Sistemas de Polinização encontrados na Mata do Buraquinho João Pessoa, PB. 


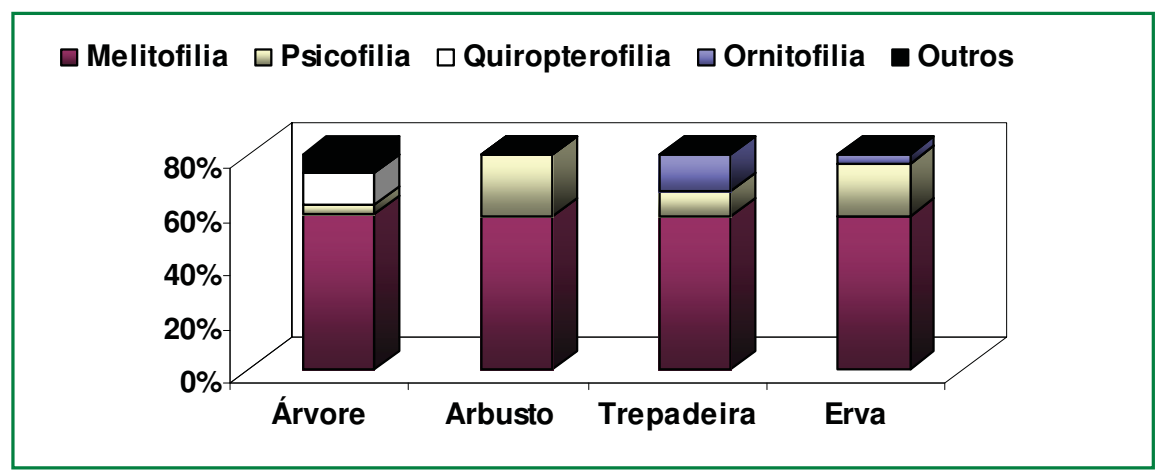

FIGURA 3: Distribuição das síndromes de polinização entre os diferentes hábitos em percentual, das espécies estudadas na Mata do Buraquinho, João Pessoa, PB.

As características gerais das flores ornitófilas foram: cores vivas, tipo tubo, de tamanho médio a grande, flores individuais e ofertando néctar. Espécies como Heliconia psittacorum L.F. (Heliconiaceae) e Cnidoscolus urens (L.) Arthur (Euphorbiaceae) são exemplos de plantas polinizadas por beija-flores. Em relação à espécie Thunbergia fragrans Roxb. (Acanthaceae), foi registrada uma ambifilia, ou seja, duas síndromes (a ornitofilia e a psicofilia).

A anemofilia foi representada por apenas uma espécie Piper marginatum Jacq. (Piperaceae). Em outros estudos como os realizados por Bawa et al. (1985) e Kang e Bawa (2003) também foram encontrados valores baixos para anemofilia, porém uma frequência alta foi observada no cerrado por Silberbauer-Gottsberger e Gottsberger (1988).

A quiropterofilia foi encontrada apenas entre as árvores, enquanto que a ornitofilia foi observada entre trepadeiras e ervas (Figura 3).

A partir dos resultados obtidos, foi possível concluir que:

- De modo semelhante a outros estudos, tanto de mata seca como úmida, a maioria das flores claras foi encontrada entre árvores e as vistosas entre ervas, o que indica a pouca relação entre cor e sistemas de polinização;

- Flores pequenas e tubulares foram a maioria entre arbustos, trepadeiras e ervas;

- Flores formando inflorescências foram comuns entre árvores, arbustos e trepadeiras, já nas ervas as flores individuais predominaram;
- Espécies hermafroditas predominaram em todos os hábitos estudados;

- As ofertas dos recursos variaram entre os hábitos estudados, sendo que o néctar predominou durante todo o período de estudo, mantendo-se mais ou menos constante tanto no período seco quanto no chuvoso;

- As síndromes de polinização identificadas (entomofilia, quiropterofilia, ornitofilia e anemofilia) variaram de acordo com os hábitos, ocorrendo regularmente em todo período de estudo;

- A melitofilia foi a síndrome mais representativa, o que confirma a importância das abelhas para a polinização na Mata do Buraquinho.

\section{Referências}

Alvino, L. D. 2005. Síndrome de polinização e dispersão das espécies vegetais ocorrentes na Serra do Bodopitá, QueimadasPB. Trabalho de Conclusão de Curso, Universidade Estadual da Paraíba, Brasil, 93pp.

Angiosperm Phylogeny Group II. 2003. An uptate of the Angyosperm Phylogeny Group classification for the orders and families of flowering plants: APG II. Botanical Journal of the Linnean Society, 141: 399-436.

Barbosa, A. A. 1997. Biologia reprodutiva de uma comunidade de Campo Sujo, Uberlândia - MG. Tese de Doutorado, Universidade Estadual de Campinas, Brasil, 180pp.

Barbosa, M. R. V. 1996. Estudo florístico e fitossociológico da Mata do Buraquinho, remanescente de Mata Atlântica em João Pessoa, Paraíba. Tese de Doutorado, Universidade Estadual de Campinas, Brasil, 135pp.

Bawa, K. S; Opler P. A. 1975. Dioecism in tropical forest trees. Evolution, 29 (1): 45-54.

Bawa, K. S.; Perry, D. R.; Beach, J. H. 1985. Reproductive biology of tropical lowland rain forest trees. I. Sexual systems and 
incompatibility mechanisms. American Journal of Botany, 72: 331-343.

Bertin, R. I. 1989. Pollination biology. In: Abrahamson, W. G. (Ed.). Plant-animal interactions. McGrawl-Hill, New York, USA, p.23-83.

Cara, P. A. A. 2006. Efeito de borda sobre a fenologia, as síndromes de polinização e a dispersão de sementes de uma comunidade arbórea na Floresta Atlântica ao norte do Rio São Francisco. Tese de Doutorado, Universidade Federal de Pernambuco, Brasil, 100pp.

Endress, P. K. 1994. Diversity and evolutionary biology of tropical flowers. Cambridge University Press, Cambridge, UK, 407pp.

Faegri, K.; Pijl, V. D. 1979. The principles of pollination ecology. Pergamon Press, Oxford, UK, 127pp.

Kang, H.; Bawa, K.S. 2003. Effects of successional status, habit, sexual systems, and pollinators on flowering patterns in tropical rain forest trees. American Journal of Botany, 90: 865-876.

Machado, I. C.; Lopes, A. V. 1998. A polinização biótica e seus mecanismos na Reserva Ecológica de Dois Irmãos. In: Machado, I. C.; Lopes, A. V. \& Porto, K. C. (Orgs). Reserva Ecológica de Dois Irmãos: Estudos em um remanescente de Mata Atlântica em área urbana. Editora Universitária da UFPE, Recife, Brasil, p.166-187.

Machado, I. C.; Lopes, A. V. 2004. Floral traits and pollination systems in the Caatinga, a Brazilian tropical dry forest. Annals of Botany, 93 (3): 365-376.

Machado, I. C.; Lopes, A. V. 2003. Recursos florais e sistemas de polinização e sexuais na Caatinga. In: Leal, I.; Tabarelli, M. \& Silva, J. M. C. da. (Orgs). Ecologia e conservação da Caatinga. Editora Universitária da UFPE, Recife, Brasil, p.515-563.

Martins, F. Q. 2005. Sistemas de polinização em fragmentos de Cerrado na região do Alto Taquari (GO, MS, MT). Tese de Doutorado, Universidade Federal de São Carlos, Brasil, 90pp.

Momose, K.; Yumoto, T.; Nagamitsu, T.; Kato, M.; Nagamasu, H.; Sakai, S.; Harrison, R. D.; Itioka, T.; Hamid, A.; Inoue, T. 1998. Pollination biology in a lowland dipterocarp forest in Sarawak, Malaysia. I. Characteristics of the plant-pollinator community in a lowland dipterocarp forest. American Journal of Botany, 85: 1477-1501.

Opler, P. A. 1980. Nectar production in a tropical ecosystem. In: Bentley, B. \& Elias T. (Eds.). The biology of nectaries. Columbia University Press, New York, USA, p.30-79.

Proctor, M.; Yeo, P.; Lack, A. 1996. The natural history of pollination. Timber Press, London, UK, 479pp.

Quirino, Z. G. M. 2006. Fenologia, síndromes de polinização e dispersão e recursos florais de uma comunidade de Caatinga no cariri paraibano. Tese de Doutorado, Universidade Federal de Pernambuco, Recife, Brasil, 164pp.

Ramírez, N.; Gil, C.; Hokche, O.; Seres, A.; Brito, Y. 1990 Biología floral de una comunidad arbustiva tropical en la Guayana Venezolana. Annals of the Missouri Botanical Garden, 77: 12601271.

Silberbauer-Gottsberger, I.; Gottsberger, G. 1988. A polinização de plantas do cerrado. Revista Brasileira de Biologia, 48 (4): 651663 